\title{
Incorporação de novas tecnologias em tomografia computadorizada
}

Eloísa M.M. Santiago Gebrin*

* Diretora do Serviço de Tomografia Computadorizada

do InRad-FMUSP

Em 1998 foi iniciada a comercialização dos aparelhos de tomografia computadorizada "multislice" ou multidetectores com aparelhos de quatro fileiras de detectores, e desde então essa nova tecnologia recebeu total aceitação médica. Sucessivamente, foram-se disponibilizando comercialmente aparelhos com 8, 10, $16 \mathrm{e}$, mais recentemente, 32 fileiras de detectores.

Esses aparelhos, juntamente com os conhecimentos adquiridos no pós-processamento de imagens, permitiram inúmeros avanços e possibilidades diagnósticas em tomografia computadorizada. Áreas que nunca foram adequadamente examinadas por tomografia computadorizada, como o coração, puderam ser analisadas por essa técnica, que continua se aprimorando, permitindo cada vez mais a avaliação não apenas anatômica como também funcional. As aplicações atuais da angiotomografia são inúmeras nas diferentes áreas, como a angiotomografia cerebral e abdominal. A angiotomografia, nas afecções abdominais, tem-se mostrado importante instrumento no planejamento pré-operatório de transplantes e tumores hepáticos, pancreáticos e renais, permitindo o adequado mapeamento das artérias e veias, bem como a avaliação de sua invasão nos casos de tumores.

Porém, mais do que todas as aplicações já estabelecidas e as que estão se desenvolvendo nos tomógrafos multidetectores, essa tecnologia impõe uma revolução no fluxo de trabalho e na dinâmica do serviço onde o aparelho está sendo implantado. A adequação operacional à essa tecnologia é fundamental para o seu funcionamento, e essa adequação envolve desde o processo de visualização das imagens adquiridas, o arquivamento a curto e longo prazos dos exames, a documentação e transferência das imagens para o médico solicitante do exame.

As estações de trabalho ("workstation") não são mais consideradas um console acessório, mas um instrumento fundamental na transformação da imagem axial para a imagem volumétrica, que pode ser apresentada com reconstruções multiplanares (coronais e sagitais), tridimensionais com nomes que ainda não foram incorporados ao vocabulário português, como o "volume rendering", o MIP ("maximum intensity projection") e o MinIP ("minimum intensity projection"). A cada exame é gerado um grande número de imagens, dependendo do protocolo utilizado. Por exemplo, num estudo do pâncreas com colimação de $1,25 \mathrm{~mm}$, em duas fases - arterial e venosa - são geradas entre 400 e 500 imagens. As estações de trabalho devem ser robustas o suficiente para a manipulação desse volume de informação. Além disso, elas devem estar disponíveis em número suficiente para atender os radiologistas do 
serviço. Nós, radiologistas, fomos treinados por anos a visualizar as imagens em filmes, e essa transição para a visualização das imagens nos monitores demanda um período de adaptação.

O armazenamento do exame é outro aspecto complexo, uma vez que cada estudo tem um tamanho que varia entre 350 megabytes a 1 gigabyte e deve estar disponível para acesso e comparação com exames a serem futuramente realizados e também para a utilização em estudos científicos. Torna-se necessária a presença de servidor com capacidade de armazenamento de alguns terabytes, interligado às estações de trabalho e ao tomógrafo "multislice" por meio de uma rede que permita o rápido trânsito das informações. É fundamental podermos contar com uma equipe de apoio com engenheiros clínicos e profissionais de informática para a resolução dos problemas, apresentando as soluções mais adequadas para os diferentes problemas.

O médico solicitante do exame precisa ter acesso ao exame. Nos hospitais que possuem PACS ("Picture Archiving and Communication Systems") integrado ao RIS ("Radiological Information System") e ao HIS ("Hospital Information System"), essa transferência de dados é facilitada, porém essa solução, em nosso meio, está restrita a apenas alguns poucos centros. Outro ponto a ser discutido é a que parte do exame o médico solicitante terá acesso: a todas as imagens adquiridas originalmente (que pode ultrapassar 1.000 imagens) ou apenas a algumas imagens selecionadas e às reconstruções multiplanares e tridimensionais. Parece-nos que essa última opção seja mais adequada, uma vez que a visualização de todas as imagens adquiridas originalmente irá, certamente, demandar um tempo demasiadamente longo para a observação. Essas imagens podem ser gravadas em CDs, porém em muitas situações os médicos ainda preferem o recebimento de filmes.

Outro fator fundamental é o planejamento dos protocolos dos exames a serem realizados, procurando a adequação dos protocolos à suspeita clínica. É importante lembramos que nem sempre o protocolo com colimações mais finas é o melhor para todos os pacientes. Além disso, a utilização do meio de contraste iodado e fatores como velocidade de injeção e tempo para início da aquisição das imagens após a sua injeção devem ser reavaliados frente às características do novo aparelho.

Os tomógrafos multidetectores, sem dúvida nenhuma, proporcionaram um número muito grande de novas aplicações para a tomografia e melhora significativa nas aplicações já existentes, mas também uma outra revolução no fluxo de trabalho do serviço de tomografia computadorizada. A adequação desse fluxo de trabalho é fundamental para a melhor relação custo/benefício dessa nova tecnologia. 